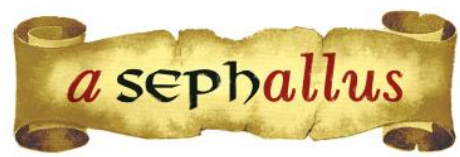

Revista aSEPHallus de Orientação Lacaniana

Núcleo Sephora de Pesquisa sobre o Moderno e o Contemporâneo

ISSN $1809-709 \mathrm{X}$

\title{
Do Nebenmensch ao Unheimlich: a presença da alteridade no processo de constituição da subjetividade
}

Perla Klautau

Psicanalista, membro efetivo do CPRJ, Professora do Programa de Mestrado Profissional e de Doutorado em Psicanálise, Saúde e Sociedade da Universidade Veiga de Almeida E-mail: pklautau@uol.com.br

Katia Faissol

Doutoranda em Psicanálise, Saúde e Sociedade na Universidade Veiga de Almeida E-mail: katia.faissol@gmail.com

\begin{abstract}
Resumo: O objetivo deste artigo é discutir a presença da dimensão alteritária no processo de constituição da subjetividade. O ponto de partida é o Nebenmensch, o "outro ao lado", que inicialmente tem a função de atender às necessidades vitais do bebê. A partir dos cuidados deste outro próximo, o movimento desejante passa a fazer parte da gramática infantil e, ao mesmo tempo, a alteridade ganha status de potência simbólica conferindo ao eu um destino alienado e, consequentemente, preso a uma alteridade fornecedora da própria identidade. $\mathrm{Na}$ adolescência, Nebenmensh, além de ser força auxiliar, se torna um objeto estrangeiro e hostil que traz em si um elemento inquietante - Unheimlich - responsável pela instalação de um estranhamento em relação à dimensão alteritária. Tal inquietação, despertada pela destituição das figuras parentais encarnadas como potências simbólicas, possibilita ao jovem remanejar suas identificações e, consequentemente, construir um norte para o ingresso na vida adulta.
\end{abstract}

Palavras-chaves: psicanálise; constituição da subjetividade; adolescência; Outro; alienação; separação.

\section{Du Nebenmensch au Unheimlich: la présence de l'altérité dans le processus de constitution de la subjectivité}

L'objectif de cet article est de discuter la présence de l'altérité dans le processus de formation de la subjectivité. Le point de départ est le Nebenmensch , «l'autre à côté », qui a initialement la fonction de répondre aux nécessités vitales du bébé. À partir de la préoccupation envers cet autrui qui est proche, le mouvement du désir commence à contribuer à la construction enfantine et, en même temps, l'altérité acquiert le statut de puissance symbolique en donnant au moi une destinée aliénée et, par conséquent, devient prisonnier d'une altérité qui produira sa propre identité. Pendant I'adolescence, le nebenmensh est une force auxiliaire et, sera aussi un objet étranger et hostile qui porte en soi un élément inquiétant - unheimliche - responsable de l'agencement d'une inquiétude envers la dimension de l'altérité. Cette inquiétude, éveillée par la destitution des modèles parentaux, incarnés comme des forces symboliques, rend possible au jeune le changement ses identifications et, par conséquent, construit une voie d'entrée en vie adulte.

Mots-clés: psychoanalyse; constitution de la subjectivité; adolescence; Autrui; aliénation; la séparation.

\section{From Nebenmensch to Unheimlich: the presence of alterity in the process of construction of the subjectivity}

The goal of this paper is to discuss the presence of alterity in the process of construction of an individual's subjectivity. The starting point is the Nebenmensch, which is the "other nearby" that has initially the objective of satisfying the vital needs of the baby. From the Nebenmensch, the longing movement becomes part of the child's grammar and, meanwhile, the alterity achieves a symbolic power status offering the self an alienated destiny and, consequently, becoming a prisoner to a subjectivity responsible for constructing the individual's identity. During adolescence, aside from being an auxiliary force, Nebenmensch becomes an external and hostile object which carries in itself a disturbing element - unheimlich - responsible for creating a feeling of strangeness with respect to the alterity dimension. This feeling of unsettlement, awakened by the destruction of the parental figures that are embodied as symbolic powers, makes it possible for the young individual to switch the objects of identifications and consequently, to construct a path towards adult life.

Key words: psychoanalysis; subjectivity construction; adolescence; the Other, alienation; separation. 


\title{
Do Nebenmensch ao Unheimlich:
}

\section{a presença da alteridade no processo de constituição da subjetividade}

\author{
Perla Klautau \& Katia Faissol
}

Para apresentar e discutir a presença da dimensão alteritária no processo de constituição da subjetividade, adotaremos como ponto de partida a noção de Nebenmensch (Freud, 1950[1895]), "outro ao lado", que inicialmente tem a função de atender às necessidades vitais do bebê. A partir dos cuidados exercidos por este tipo de alteridade, a demanda por alimento gradualmente vai se convertendo em demanda de amor. Ao longo deste processo, o movimento desejante vai passando a fazer parte da gramática infantil e, ao mesmo tempo, o outro vai ganhando status de potência simbólica. Fato este que confere ao eu um destino alienado e preso a uma alteridade fornecedora da própria identidade. Nesse tempo inicial da constituição da subjetividade, a criança só possui uma escolha: a de alienar-se em um significante-mestre obtido a partir do campo do Outro. Nesta operação, a criança acaba perdendo uma parte de seu ser. A parte perdida se torna distinta da identificação com o significante-mestre e possibilita o segundo tempo da constituição do sujeito: a separação. Quando o sujeito se depara com o registro faltoso da dimensão alteritária, traduzida por meio do desaparecimento de qualquer imagem identificatória, o Nebenmensch passa, simultaneamente, a ser concebido como um objeto de satisfação ao qual o sujeito se aliena e, também, como um objeto estrangeiro e hostil - Unheimlich (Freud, 1919) - do qual o sujeito precisa se separar. Nesse espaço de tempo, um elemento inquietante instala uma estranheza que funcionará como mola propulsora para a separação. Movimentos como este são imperiosos para que o sujeito conquiste a possibilidade de construir para si uma posição singular no mundo.

\section{Nebenmensch: a presença da alteridade como potência simbólica}

Com o intuito de fundamentar o papel desempenhado pela alteridade no processo de constituição da subjetividade, Freud (1950[1895]), em seu "Projeto para uma psicologia científica", descreveu a presença do Nebenmensch - o homem ao lado, o próximo - como uma força auxiliar, como uma espécie de primeira potência responsável pelo acesso do bebê ao mundo simbólico. Para tal, Freud (1950[1895]) empreendeu uma tentativa de descrever o funcionamento do aparelho psíquico com o intuito de representar quantitativamente os processos psíquicos a fim de inserir a psicologia no campo das ciências naturais. $O$ ponto de partida adotado em suas reflexões remete à frequência constante com que o sistema nervoso é bombardeado por estímulos provenientes de excitações, tanto internas quanto externas, e ao entendimento de que o cérebro é um órgão de homeostase. Por trás disto, há o postulado que rege a regulação do funcionamento psíquico: o aumento das excitações está associado ao desprazer e sua diminuição ao prazer. De acordo com tal raciocínio, cabe ao sistema nervoso zelar pela homeostase em sua permanente atividade de 
regulação das relações do organismo com o meio. Para isto, dois princípios serviram de fundamento para ordenar a quantidade de excitações externas e internas: os princípios de inércia e de constância.

A função de ambos é eliminar, tanto quanto possível, a carga de excitação recebida a fim de restabelecer o estado de repouso. Tal mecanismo funciona muito bem quando o que está em questão diz respeito aos estímulos externos, já que estes podem ser descarregados segundo o modelo de funcionamento do arco reflexo - "a origem da ação fornece o motivo para o movimento reflexo" (Freud, 1950[1895], p. 404). Quando a questão recai sobre os estímulos endógenos, o princípio de inércia se revela incapaz de dar conta de excitações ligadas às exigências da vida (not des lebens) como, por exemplo, a fome e a sexualidade; das quais não é possível fugir. Ou seja, o modelo do arco reflexo, não serve mais como paradigma para a regulagem dos estímulos endógenos, pois torna-se necessária a realização de uma "ação específica" (Freud, 1950[1895], p. 405):

O organismo humano é, a princípio, incapaz de promover essa ação específica. Ela se efetua por ajuda alheia, quando a atenção de uma pessoa experiente é voltada para o estado infantil por descarga através da via de alteração interna. (Freud, 1950[1895], p. 431)

O trecho acima deixa claro que a ação específica é proveniente do mundo externo. Isto significa que o aparelho psíquico depende de um outro próximo (Nebenmensch) capaz de acolher, por exemplo, o choro resultante da fome, e de executar a atividade necessária para auxiliar a remoção do estímulo endógeno. Tal necessidade expõe o fracasso do funcionamento solipsista do aparelho psíquico e marca definitivamente a função crucial da alteridade nos primórdios da construção do psiquismo. É justamente neste contexto que o princípio de constância entra em ação: "o sistema nervoso é obrigado a abandonar sua tendência original à inércia" (Freud, 1950[1895], p. 406). É preciso haver tolerância ao acúmulo de excitação suficiente para satisfazer às exigências de uma ação específica. Este acúmulo deve ser mantido constantemente no mais baixo nível possível a fim de manter a homeostase. Sendo assim, a postulação da ação específica e do princípio de constância colocam em cena a função do Nebenmensch no percurso do bebê na busca de satisfação dos seus estímulos endógenos: a satisfação das urgências provenientes das fontes somáticas dependerá do mundo externo, do cuidador que garantirá a sobrevivência do infante:

Quando a pessoa que ajuda executa o trabalho da ação específica no mundo externo para o desamparado, este último fica em posição, por meio de dispositivos reflexos, de executar imediatamente no interior de seu corpo a atividade necessária para remover o estímulo endógeno. A totalidade do evento constitui então a experiência de satisfação, que tem consequências mais radicais no desenvolvimento das funções do indivíduo. (Freud, 1950[1895], p. 431) 
Diante do que foi dito, não resta dúvidas de que a experiência de satisfação é tomada por Freud como paradigma para o entendimento do que caracteriza a subjetividade humana e, sobretudo, para o reconhecimento do papel crucial do outro (Nebenmensch) no que diz respeito à introdução do bebê na ordem simbólica. Sendo assim, a totalidade do evento (experiência de satisfação) imprime uma marca psíquica que reúne o desamparado (bebê) e a pessoa que ajuda (Nebenmensch): a experiência de desconforto traz atrelada a si agonia e vazio causados pela fome que podem ser transformados em experiência de satisfação quando o outro materno realiza uma ação específica proporcionando o leite que aplaca a agitação e o choro. A marca psíquica, produzida a partir da inscrição da imagem mnêmica da experiência de satisfação, poderá ser acessada em um estado de desequilíbrio, ou seja, quando a fome reaparece. Desta forma, quando um estado de urgência se faz presente, há uma ativação da imagem mnêmica que permite reconstruir a presença do objeto a partir de uma alucinação da experiência de satisfação. Este movimento vai colocando o bebê em relação com as propriedades qualitativas que acompanham a percepção e, gradualmente, vai dando corpo à memória. É importante ressaltar que, pela via da alucinação, a criança tem acesso somente ao registro mnêmico do objeto de satisfação já que o objeto primeiro foi perdido. Daí por diante, tanto a satisfação quanto seu objeto passam a ser buscados na intenção de serem revividos em sua plenitude. Assim se inscreve a marca da primeira perda que precipita um movimento, inevitavelmente fracassado, de busca da reedição da satisfação originária.

A partir do que foi exposto, torna-se possível perceber que, por intermédio do atendimento das necessidades desempenhado pelo outro semelhante, o estado de urgência, despertado pela fome, vai sendo inserido no universo simbólico. Desta forma, o estado de urgência vai se convertendo em desejo. Chegamos a um ponto em que é possível notar que a máquina fisicalista proposta por Freud sofreu uma metamorfose (Bezerra Jr., 2013). A transformação em questão encontra-se diretamente atrelada à entrada em cena do Nebenmensch. A partir da ação específica, realizada para aplacar o estado de urgência, o cuidar e a presença de um outro passam a fazer parte do processo de constituição da subjetividade. Isto significa que, ao se ocupar do bebê, o Nebenmensch atua como provedor não só do objeto para a satisfação dos estímulos endógenos, mas também de uma gama de significantes responsáveis pela introdução do sistema simbólico.

No seminário dos anos de 1956-1957, Lacan fornece uma descrição da experiência de frustração que, de certa forma, torna complexa a vivência de satisfação descrita por Freud. Ao abordar a conversão do estado de urgência em desejo, Lacan (1956-1957) introduz para os ouvintes de seu seminário a noção de frustração que, ao lado da castração e da privação, tornou-se um dos termos de referência para tratar da questão da falta do objeto. Lacan tomou como ponto de partida as primeiras relações da criança com a mãe para situar a dialética da frustração em relação à ordem simbólica e à realidade. A noção de frustração se refere às primeiras experiências do bebê diante de um objeto pertencente à realidade compartilhada, cujo protótipo é o seio materno, com referência 
ao qual a criança vai se posicionar. Nesse sentido, é sempre de um objeto pertencente à realidade que a criança sente falta: "A frustração é, por essência do domínio da reivindicação. Ela diz respeito a algo que é desejado e não obtido, mas que é desejado sem nenhuma referência a qualquer possibilidade de satisfação nem aquisição" (Lacan, 1956-1957, p. 36). Dessa maneira, Lacan aproxima a noção de frustração do modo de reivindicação que pode ser concebido como um prejuízo, um dano, ou uma lesão. Seguindo essa premissa, o objeto antes de ser percebido como tal, pode ser colocado em cena na dialética que envolve o bebê e a sua mãe, apreendida, neste momento, através do seio que o alimenta. É a partir da falta da mãe, ou do seio, decorrente de um certo ritmo marcado entre ausências e presenças, que o bebê vai estabelecendo um certo modo de relação com o mundo. A mãe, no papel de agente, pode responder ou não ao apelo de seu filho e, dessa forma, a partir de períodos alternados de presenças e ausências, ela oferece a oportunidade da criança articular uma relação que faz parte da realidade compartilhada com uma relação simbólica. Nesta dialética, a mãe torna-se uma potência, cuja presença ou ausência pode gerar sentimentos e afetos no campo das relações da criança. Sendo assim, a posição do objeto, tal como a da mãe, sofre uma inversão: de pertencente ao campo da realidade, torna-se simbólico. "Estes objetos que eram até então, pura e simplesmente, objetos de satisfação, tornam-se por parte dessa potência, objetos de dom" (Lacan, 1956-1957, p. 69).

Dessa forma, é possível perceber que o Nebenmensch, o outro ao lado capaz de realizar a ação específica, se torna potência simbólica. Na teoria lacaniana, esta função simbólica é representada pela letra $A$, pois, em francês, outro é autre: "há dois outros que se deve distinguir, pelo menos dois - um outro com $A$ maiúsculo e um outro com a minúsculo, que é o eu. O Outro, é dele que se trata na função da fala" (Lacan, 1954-1955, p. 227). Assim, $A$ ou (grande) Outro designa a potência simbólica que atesta a prevalência da linguagem já no estabelecimento das primeiras relações do bebê com a alteridade.

Para entender melhor o que foi dito acima, torna-se necessário recorrer brevemente à concepção lacaniana do estádio do espelho. Lacan, em 1949, no artigo "O estádio do espelho como formador da função do eu", parte dos primeiros meses de vida do bebê humano, aproximadamente entre os seis e dezoito meses, com o intuito de ilustrar o nascimento do eu. Ao recorrer aos experimentos de Henry Wallon realizados com crianças e animais frente ao espelho, Lacan demonstra que, por intermédio da imagem do corpo do outro vista em sua totalidade, o bebê obtém, por antecipação, a sensação de unificação corporal. Desta forma, a criança se depara com sua imagem tomada como objeto de investimento libidinal, e se identifica com esta, reconhecendo-se, portanto, na imagem percebida. Nessa operação, torna-se importante ressaltar que é somente um terceiro, geralmente a mãe, que sustenta a relação dual do eu com a sua imagem especular. Isto institui uma relação de dependência que, ao mesmo tempo, atesta a emergência do eu e confere-Ihe um destino alienado e preso a uma alteridade fornecedora da própria identidade. É nesse sentido que Lacan enfatiza que o desejo do Outro passa a ter prevalência 
sobre o sujeito. Sendo assim, o Outro representa o todo-poderoso simbólico que pode ser entendido como a potência encarnada pela mãe no momento em que a criança lhe endereça uma demanda.

Em 1964, no seminário Os quatro conceitos fundamentais da psicanálise, Lacan recorre à matemática, mais especificamente, à teoria dos conjuntos para estabelecer a noção de alienação como o primeiro tempo da constituição da subjetividade. Ao alienar-se no Outro, o desejo apresenta-se como condição absoluta pelo fato de ser com ele que a criança se identifica. Deste modo, inicialmente, a criança só possui uma escolha, a de alienar-se em um significante mestre obtido a partir do campo do Outro, perdendo, assim, uma parte de seu ser. Esta parte perdida e distinta da identificação com o significantemestre possibilita um confronto com o desejo do Outro: "Nos intervalos do discurso do Outro, surge na experiência da criança, o seguinte, que é realmente destacável - ele me diz isso, mas o que é que ele quer?' (Lacan, 1964, p. 203). Tal indagação traduz a impossibilidade de decifrar o desejo do todo-poderoso simbólico, abrindo, assim, um abismo entre o sujeito e o Outro.

Quando o sujeito se depara com a falta do Outro, traduzida por meio do desaparecimento de qualquer imagem identificatória, o Nebenmensch pode ser concebido, ao mesmo tempo, como um objeto de satisfação no qual o sujeito se aliena e como um objeto estrangeiro e hostil do qual o sujeito precisa se separar. Neste momento, um elemento inquietante (Unheimlich) instala uma estranheza em relação ao Outro. Tal inquietação funcionará como mola propulsora para que o sujeito em constituição possa se separar do Outro. Deste modo, a parte perdida e distinta da identificação com o significante-mestre também possibilita o segundo tempo da constituição do sujeito: a separação.

Diferentemente da alienação, a separação não é um destino, pelo contrário: "a separação consiste na tentativa por parte do sujeito alienado de lidar com esse desejo do Outro na maneira como ele se manifesta no mundo do sujeito" (Fink, 1998, p.73). Para ilustrar a posição adotada pelo sujeito na operação de separação, Lacan (1964) faz uso do trocadilho se parare, se parerelaborado a partir da palavra francesa separare que, traduzida para o português, significa separar, e o trocadilho significa se parir. Este jogo de palavras exprime o cerne da operação de separação que consiste, simultaneamente, no advento do sujeito desejante e na percepção do Outro como faltoso do qual ele se descola. Tais movimentos são imperiosos para que o sujeito deixe de encarnar o desejo do Outro e conquiste a possibilidade de construir para si uma posição singular, conseguindo, assim, transitar entre a alienação e a separação na busca da assunção do seu desejo.

\section{Unheimlich e o despertar da adolescência}

Em seu artigo "Das Unheimlich", Freud (1919) percorreu o campo da estética para explorar os diversos sentidos da palavra Unheimlich, com o intuito de examinar as formas como afloram sentimentos duplos e ambivalentes. Neste contexto, Freud constrói sua argumentação em torno da ambiguidade contida em unheimlich: heimliche pode significar tanto familiar quanto secreto e oculto. Significados que aproximam heimlich de seu oposto, unheimlich, traduzido para o português tanto como estranho quanto como inquitetante ${ }^{1}$. Se prestarmos atenção à grafia dos termos em questão, 
é possível perceber que unheimlich contém em si heimlich. Tal fato permite relacionar unheimlich ao que é, ao mesmo tempo, familiar e desconhecido. Tais variações remetem a sentimentos que fazem parte das vivências primitivas do sujeito, prontos para emergirem em determinados momentos da vida com uma roupagem nova.

$\mathrm{Na}$ puberdade, essa nova roupagem é imposta pelas transformações corporais que despertam o jovem do período de latência. As vivências infantis adormecidas são despertadas a partir da imposição do corpo púbere que deflagra uma sensação de estranhamento. Assim, a adolescência desabrocha com o despertar da puberdade, trazendo à consciência inquietudes que permaneciam adormecidas. Em seu estudo das diferentes acepções do termo Unheimlich, Freud (1919) nos fornece um significado que pode ser articulado ao momento transitório da adolescência: "seria tudo o que deveria permanecer secreto, oculto, mas apareceu" (Freud, 1919, p. 338). E agora? Como e onde buscar as novas referências? Quando o sujeito adolescente expõe o que deveria permanecer secreto e recalcado, os pais deixam de reconhecer naquele filho o fruto de seus esforços, assim como o próprio não se reconhece mais a partir do olhar de seus pais, gerando um sentimento de estranheza conferido na solidão que impulsiona o adolescente a buscar seus pares.

A origem do questionamento dos adolescentes em relação ao seu lugar no mundo adulto é resultante do abalo narcísico sofrido em virtude do afrouxamento identificatório que acaba desencadeando a destituição das figuras paternas da posição de ideal. Freud afirma que "tudo que há de admirável e de indesejável na nova geração é determinado por esse desligamento do pai" (Freud, 1919, p. 288). A premência do adolescente em desligar-se das identificações parentais exigirá um árduo trabalho de elaboração, que envolverá a percepção do desamparo fundamental e a necessidade de assumir seu desejo. Imerso neste cenário, o jovem também se depara com a castração de seus pais, destituindo-lhes, mais uma vez, do lugar de ideal. A consequência disto é um abalo à consistência do Outro que traz consigo o sentimento de desamparo. Diante da percepção do vazio presente no lugar ocupado pelo desejo dos pais, o adolescente experimenta uma miscelânia de sentimentos que, quando exacerbada, o conduz à perda das referências identificatórias, abrindo e abalando as bases fincadas a partir do ideal de seus pais. Dessa forma, a perda das referências do Outro, em um primeiro momento, é vista como ameaçadora, e será encarada como incerta, impondo sucessivos períodos de conflitos, hesitações e incertezas:

[...] o adolescente está sempre confrontado, se não com a pane, ao menos a um risco de pane, porque ele deve de novo, e precisamente no a posteriori, realizar uma série de operações fundadoras, cuja efetuação infantil está recolocada na ordem do dia. Da identificação estrita ou familiar à identificação geral no social, há um hiato que exige do sujeito uma operação de múltiplas faces [...]. (Rassial, 1997, p. 39-40) 
Rassial (1997) utiliza a metáfora pane como tradução palavra inglesa breakdown que, ao ser convertida para o português, pode ser traduzida como quebra de desenvolvimento, caracterizando, assim, o golpe do real. Nesta acepção, segundo o autor, é possível conceber a adolescência como um momento de pane (breakdown). Os riscos de pane trazem consigo um movimento produtivo de separação do Outro que produz diferença e remonta o cenário infantil com a autoria do sujeito adolescente. A perspectiva da riqueza trazida por este movimento, ainda desconhecido pelo próprio adolescente, pode ser encontrada no questionamento de Dostoievsky (1875): "como eu era todo moldado com as ideias dos outros, onde poderia encontrar as minhas próprias, no momento em que tinha necessidade delas para tomar uma decisão?" (Rassial, 1997, p. 87).

Diante desta questão, é possível afirmar que, na busca por uma resposta, Nebenmensch e Unheimlich se articulam: encontram-se no eco do real do corpo púbere através do viés da fantasia na tentativa de servir como base para novas identificações. Estas funcionarão como alicerces dos vínculos dos novos papéis sociais que o sujeito adolescente passará a ter a partir da elaboração dos ideais infantis, gerando, além das transformações corporais, transformações de seus desejos.

A operação transitória, típica da adolescência, traz em si Unheimlich na medida em que o retorno do recalcado emerge dando a sensação para o jovem de que sua experiência é algo estranhofamiliar. A revivência avassaladora do que encontrava-se adormecido desperta um elemento inquietante (Unheimlich) que instala uma estranheza-familiar em relação ao (re)florescer da sexualidade no sujeito adolescente. Esse movimento acarreta no jovem inquietudes e reflexões sobre a vida e a morte, remetendo-o ao encontro com o Outro em sua dimensão faltosa. Dessa forma, a transitoriedade vivida na adolescência requer, concomitantemente, registros em novos campos de palavras, de objetos e de outros; novos significantes, na tentativa de refazer as identificações infantis. Nesse percurso, Nebenmensch e Unheimlich articulam-se para proteger o eu da ruptura imposta pelo real do corpo que traz em si a ambiguidade da "garantia da sobrevivência" e o "inquietante mensageiro da morte" (Freud, 2014[1919], p. 352). É justamente essa articulação que atua como mola propulsora para que o sujeito adolescente possa, em seu tempo lógico, remanejar suas identificações e, assim, construir um norte para o ingresso na vida adulta.

\section{Considerações finais: entre Nebenmensch e Unheimlich}

Freud, em 1895, no texto "Projeto para uma psicologia científica, utiliza a palavra Nebenmensh para fazer referência ao semelhante que fornece ajuda na realização de uma ação específica. Desta forma, Nebenmensh pode ser entendido como aquele que se relaciona com o bebê possibilitando sua sobrevivência, fornecendo o alicerce da vida e funcionando como uma força auxiliar. Como vimos, ao longo do processo de constituição da subjetividade, o Nebenmensh vai se tornando também um objeto que comporta em si algo estranho-familiar: na adolescência, a 
familiaridade de Nebenmensh se torna estranha, fazendo do semelhante um objeto estrangeiro e hostil (Unheimlich).

Como foi visto, os sentimentos despertados pelo misto de estranheza e familiaridade remetem o sujeito a vivências primitivas que podem ser atualizadas durante adolescência. Neste sentido, de acordo com Rassial (1997), a adolescência pode ser concebida como um segundo tempo do estádio do espelho (Lacan, 1949). Para lidar com este après-coup da primeira infância, o adolescente precisa se apropriar de seu novo corpo que, diante do espelho, deflagra um sentimento de não pertencimento e de estranhamento. As transformações pubertárias vão impor ao sujeito ebulições que necessitam de um novo processo de (re)conhecimento de sua imagem e de seu lugar no campo do Outro. Os objetos voz e olhar, assim como a rede de significantes estabelecida ao longo da infância, serão remodelados a partir da reconstrução do estádio do espelho, que, de forma lúdica, pode ser apreendida no diálogo estabelecido entre a personagem Alice com a lagarta:

"Quem é você?", perguntou a lagarta.

(...) "Eu... Eu não sei direito, senhora, não no momento... Pelo que sei quem eu era antes de acordar hoje de manhã, mas acho que devo ter mudado várias vezes desde então".

(...) "Explique-se!"

"Receio que não possa me explicar senhora, (...) porque não sou eu mesma, sabe" (Carroll, 2014, p. 61)

As mudanças no corpo e na posição do sujeito adolescente desestabilizam a imagem especular: ele não sabe mais quem é, nem qual é sua imagem no espelho do Outro. O jovem recua diante da voz e do olhar materno e dos significantes que o designaram ao longo da infância. $O$ trabalho de reconstrução de um novo espelho na busca de seu novo lugar social se faz necessário. O imperativo das mudanças corporais no corpo púbere e o impacto que trazem em si deflagram uma pane no sujeito, evidenciando, como afirma Freud (1923), que "o eu é antes de tudo corporal". A partir dessas mudanças o adolescente precisará reorganizar a imagem especular de seu corpo, integrada e constituída na tenra infância, se (re)apropriando da mesma para alicerçar o reconhecimento de sua imagem adulta através da alienação de sua primeira encarnação do Outro a mãe. A voz é considerada por Lacan como um objeto primordial na constituição do sujeito. Assim, a surpresa da personagem Alice, no diálogo acima, exemplifica o estranhamento sentido pela jovem com a imposição das ebulições pubertárias.

A imposição do significante que a mãe atribui ao bebê detém o poder de designar o lugar deste na estrutura familiar. É uma iniciação fálica que autorizará a nomeação no campo do Outro a partir do Nome-do-Pai como significante, ou seja, da metáfora paterna. Essa metáfora impõe a substituição do desejo da mãe dando a possibilidade à criança de substituir o lugar da mãe por seu 
símbolo, o que facilita suportar a sua ausência. A reestruturação dessa complexa estrutura especular exige do adolescente uma reorganização do valor e da função dos objetos voz e olhar, assim como dos seus significantes, a fim de que possa validar a inscrição do Nome-do-Pai para além da metáfora paterna.

A premência do afrouxamento identificatório do adolescente em relação às suas figuras parentais inaugura a possibilidade de construção de uma nova percepção destes. A partir daí, o adolescente consegue descerrar o véu que o levará forçosamente à busca de uma posição subjetiva no mundo. O Nome-do-Pai viabiliza o processo de subjetivação a partir da operação da metáfora paterna, o que faculta a estruturação do recalque originário. A base dessa estruturação são as substituições dos significantes, possibilitando a função paterna como uma metáfora e fazendo com que o Nome-do-Pai entre em substituição ao falo enquanto objeto de desejo da mãe. Assim, a instituição do Nome-do-Pai viabiliza o sujeito circular pelo Outro.

$\mathrm{Na}$ adolescência, posto que há um retorno ao estádio do espelho, não será mais um dos progenitores que apresentará o novo mundo ao jovem, essa função passa a ser de seus pares. Logo, o desmoronamento do modelo infantil sustentado pela crença no poder soberano do Outro leva o adolescente a perceber a falência da pretensa solidez das figuras parentais, e impulsiona-o a deparar-se com a possibilidade de criação de novos suportes ou novos Nomes-do-Pai. É partindo de uma posição possível de ser alcançada que o sujeito adolescente, ao percorrer seus caminhos, busca um lugar para existir. A fantasia, muitas vezes familiar, estranha e inquientante, constitui-se, ao mesmo tempo, como mola propulsora e amparo para a busca do adolescente por seu lugar no mundo.

\section{Nota:}

${ }^{1}$ A tradução realizada pela editora Imago utiliza a palavra estranho, e a tradução da editora Companhia das Letras utiliza a palavra inquietante. Esta última foi a versão utilizada no presente artigo.

\section{Referências bibliográficas}

Bezerra Jr., B. (2013). Projeto para uma Psicologia Científica: Freud e as neurociências. Rio de Janeiro: Civilização Brasileira.

Carroll, L. (1865). As Aventuras de Alice no País das Maravilhas. São Paulo: Globo S.A. 2014.

Dostoievsky, F. (1875). O Adolescente. Rio de Janeiro: José Olympio, 1960.

Fink, B. (1988). O sujeito lacaniano: entre a linguagem e o gozo. Rio de Janeiro: Zahar.

Freud, S. (1990). Projeto para uma psicologia científica. In J. Salomão (Trad.). Edição Standard Brasileira das Obras Psicológicas Completas de Sigmund Freud (vol. 1, pp. 403-466). Rio de Janeiro: Imago (Trabalho original publicado em 1895[1950]). 
Freud, S. (1976). Algumas Reflexões sobre a Psicologia Escolar. In J. Salomão (Trad.). Edição Standard Brasileira das Obras Psicológicas Completas de Sigmund Freud (vol. 13, pp. 281288). Rio de Janeiro: Imago (Trabalho original publicado em 1914).

Freud, S. (2010). O Inquietante. In Paulo Cesar Souza (Trad.). História de uma neurose infantil ("O homem dos lobos"), além do princípio do prazer e outros textos (vol. 14, pp. 328-376). São Paulo: Companhia das letras (Trabalho original publicado em 1919).

Freud, S. (2011). O Eu e o Id. In Paulo Cesar Souza (Trad.). O Eu e o Id, "autobiografia" e outros textos (vol. 16, pp. 13-60). São Paulo: Companhia das letras (Trabalho original publicado em 1923).

Lacan, J. (1998). O estádio do espelho como formador da função do eu tal como nos é revelada na experiência psicanalítica. In Escritos. Rio de Janeiro: Zahar (Trabalho original publicado em 1949).

Lacan, J. (1997). O seminário, livro 2: o eu na teoria de Freud e na técnica da psicanálise. Rio de Janeiro: Zahar (Trabalho original publicado em 1954-1955).

Lacan, J. (1995). O seminário, livro 4: a relação de objeto. Rio de Janeiro: Zahar (Trabalho original publicado em 1956-1957).

Lacan, J. (1985). O seminário, livro 11: os quatro conceitos fundamentais da psicanálise. Rio de Janeiro: Zahar (Trabalho original publicado em 1964).

Rassial, J. J. (1997). A Passagem Adolescente, da família ao laço social. Porto Alegre: Artes e Ofícios Editora Ltda.

Citacão/Citation: Klautau, P. \& Faissol, K. (nov. 2015 a abr. 2016). Do Nebenmensch ao Unheimlich: a presença da alteridade no processo de construção da subjetividade. Revista aSEPHallus de Orientação Lacaniana, 11(21), 66-76. Disponível em www.isepol.com/asephallus. doi: 10.17852/1809709x.2019v11n21p66-76.

Editor do artigo: Tania Coelho dos Santos.

Recebido/Received: 02/02/2016 / 02/02/2016.

Aceito/Accepted: 15/02/2016 / 02/15/2016.

Copyright: (C) 2016 Associação Núcleo Sephora de Pesquisa sobre o moderno e o contemporâneo. Este é um artigo de livre acesso, que permite uso irrestrito, distribuição e reprodução em qualquer meio, desde que o autor e a fonte sejam citados/This is an open-access article, which permites unrestricted use, distribution, and reproduction in any medium, provided the author and source are credited. 